\title{
Analysis of Knowledge Graph on the Subject of Domestic Human Resource Management Practice
}

\author{
Xiaona Bao ${ }^{1, *}$, Chuan $\mathrm{Xu}^{1}$, Xiaona Bao ${ }^{1}$ \\ ${ }^{1}$ Department of Human Resource Management, Dalian University of Technology, Dalian, Liaoning, China
}

\begin{abstract}
Human resource is contained in the knowledge, ability and employee relationship of the employees in the enterprise, and it is the competitive advantage that the competitors can not imitate, and the effective practice of human resources management can promote the organization innovation. This study uses the knowledge map research method to analyze the journals on the practical subject of human resources management in China, taking the periodicals included in the core journals from 1994 to 2018 as the research object, and using citespace software to analyze the journals from the literature authors and the publishing organizations. By drawing the map of scientific knowledge, we can identify the current situation and research focus in China.
\end{abstract}

\section{Introduction}

Human resources have become a strategic resource of an enterprise and the most important resource of an enterprise or organization. Scholars at home and abroad have made rich research results on "human resources" and "human resource management". In order to clearly present the context of existing research results, the scientific knowledge map research method is used to analyze the retrieved literature, grasp the hot changes and development of human resource management research, and provide reference and reference for the theoretical research and practice of human resource management.

\section{Data sources and research methods}

\subsection{Data collection status}

The Chinese literature uses CNKI database as the basic data source. Since the information of irrelevant literature will affect the accuracy of citespace analysis, the resource type selects the journal, the subject is "Human Resource Management Practice", and the core journal is selected for retrieval, and the time is not set. And finally got 1066 literature records, the time span is from 1994 to 2018.

\subsection{Introduction to research software and principles}

Knowledge graph is a method of visual analysis of a research field through various means such as data mining, scientific measurement, information analysis, and graph drawing. It can not only reveal the static knowledge structure frame diagram,but also display Dynamic spectrum of knowledge development process [2]. Cite Space software developed by Dr. Chaomei Chen from the School of Information Science and Technology of Drexel University in the United States was used to analyze the literature based on the JAVA language. The software version used in this study was Citespace5.3.R4. Through map drawing and data analysis, combined with quantitative and qualitative analysis, the paper author's cooperation network analysis, keyword co-occurrence network analysis, etc. are carried out. Analyzing the keyword co-occurrence network can find research hotspots; through the analysis of the authors and the cooperation network with high frequency of articles, the core scholars and their academic exchange relationships within the research topic can be found.

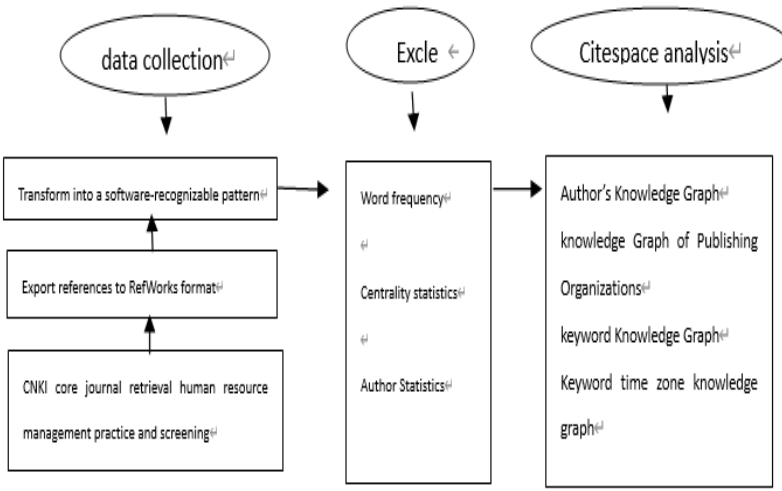

Fig. 1 Data acquisition and analysis process 


\section{Visual analysis of research focus and development trend}

\subsection{Analysis of the author's knowledge graph}

Scientific research cooperation is the driving force for the development of science today. By studying the mainstream academic groups of the theme of human resource management practice, it is helpful to discover the development law of the theme. Figure 2 shows a oneyear slice. The top 50 of the introduction includes 106 authors, 75 nodes, and no crops. Table 3 shows that the author with the most essays is Professor Zhao Shuming. The Burst value of Professor Peng Jianfeng, Professor Peng Jisheng, Professor Fang Hongjun and Professor Xing Zhouling is non-zero, and they are the "emerging figures" of this topic that need to be paid attention to [3]. Professor Liu Shanshi is the only author whose betweenness centrality is not zero, indicating that Professor Liu promotes the connection between different scholars. Try to ensure that lines are no thinner than 0.25 point.

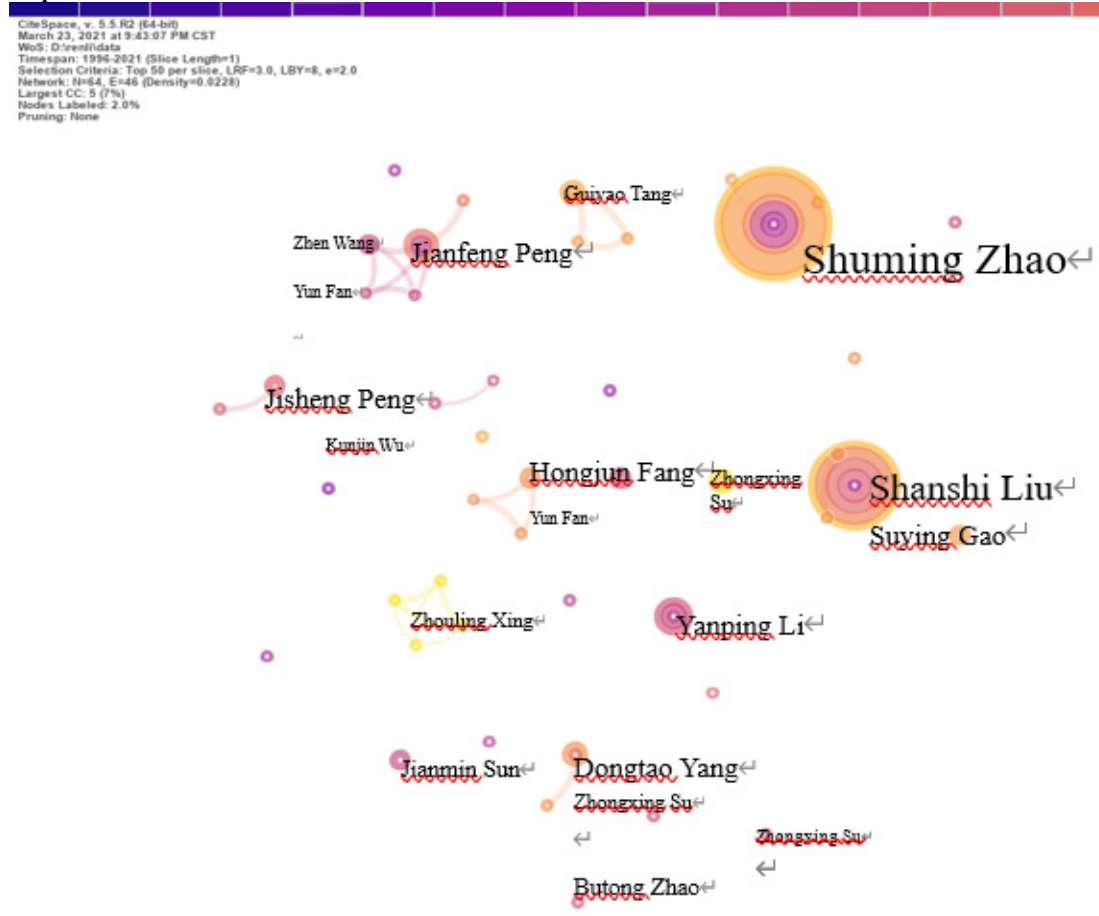

Fig.2 Author's Co-occurrence Knowledge Graph

Table 1 Authors with more than 5 articles

\begin{tabular}{|c|c|c|c|c|c|c|c|}
\hline Author & Freq & Burst & Centrality & Author & Freq & Burst & Centrality \\
\hline Shuming Zhao & 32 & & & Guiyao Tang & ? & & \\
\hline Shanshi Liu & 29 & & 0.01 & Zhouling Xing & r & 3.37 & \\
\hline Yanping Li & 9 & & & Zhen Wang & 7 & & \\
\hline Jianfeng Peng & 9 & & 3.96 & Zhongxing Su & t & & \\
\hline Jisheng Peng & 9 & 3.33 & & Yun Fan & t & & \\
\hline Hongjun Fang & 9 & 4.93 & & Suying Gao & ( & & \\
\hline Dongtao Yang & 9 & & & Kunjin Wu & 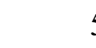 & & \\
\hline Jianmin Sun & 8 & & & Butong Zhao & 5 & & \\
\hline
\end{tabular}

\subsection{Knowledge Graph Analysis of Research Institutions}

Figure 3 shows the cooperative knowledge map of teaching and research institutions on the theme of human resource management practice from 1994 to 2018. The annual ring represents the history of posting [4], the size of the node and node label text represents the number of postings in 24 years, and the connection between nodes Represents the cooperative contact of the issuing agency 
[5]. As shown in Figure 3 and Table 2, a total of 76 institutions have published core journals on this topic. The business school of Nanjing University has the largest number of articles with 72 articles, the second is Renmin University of China, with 54 articles, and the third is School of Business Administration, South China University of Technology, published 45 articles. Among them, the central intermediary of the School of Business of Renmin University of China and the School of Management of Shandong University is not 0 , which proves that the scholars of this institution have academic cooperation and exchanges with other institutions.

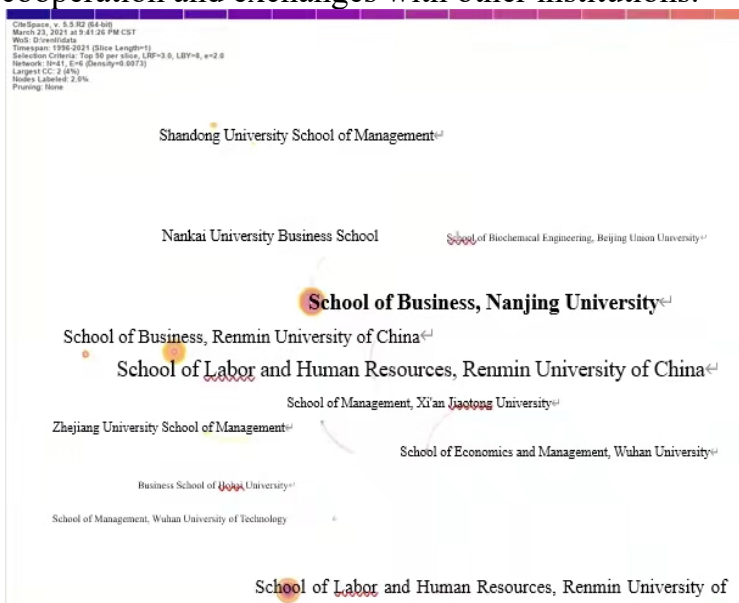

Fig. 3 Knowledge map of publishing organizations

Table 2 Cooperative knowledge map of issuing institutions

\begin{tabular}{ccc}
\hline mechanism & Freq & $\begin{array}{c}\text { Cent } \\
\text { rality }\end{array}$ \\
\hline $\begin{array}{c}\text { School of Business, Nanjing University } \\
\text { School of Labor and Human Resources, }\end{array}$ & 72 & 0 \\
$\begin{array}{c}\text { Renmin University of China } \\
\text { School of Business Administration, South } \\
\text { China University of Technology }\end{array}$ & 45 & 0 \\
$\begin{array}{c}\text { School of Business, Renmin University of } \\
\text { China }\end{array}$ & 17 & 0.01 \\
$\quad \begin{array}{c}\text { Shandong University School of } \\
\text { Management }\end{array}$ & 14 & 0.01 \\
$\begin{array}{c}\text { Zhejiang University School of Management } \\
\text { School of Management, Xi'an Jiaotong } \\
\text { University }\end{array}$ & 13 & 0 \\
$\begin{array}{c}\text { School of Economics and Management, } \\
\text { Wuhan University }\end{array}$ & 9 & 0 \\
$\begin{array}{c}\text { Nankai University Business School } \\
\text { School of Biochemical Engineering, } \\
\text { Beijing Union University }\end{array}$ & 8 & 0 \\
$\begin{array}{c}\text { School of Management, Wuhan University } \\
\text { of Technology }\end{array}$ & 6 & 0 \\
$\begin{array}{c}\text { Business School of Hohai University } \\
\text { Salo }\end{array}$ & 6 & 0 \\
\hline
\end{tabular}

\subsection{Keyword co-occurrence knowledge graph analysis}

Import the data source into the citespace software, set the node type to keywords, and the default system settings to get the keyword co-occurrence map, as shown in Figure

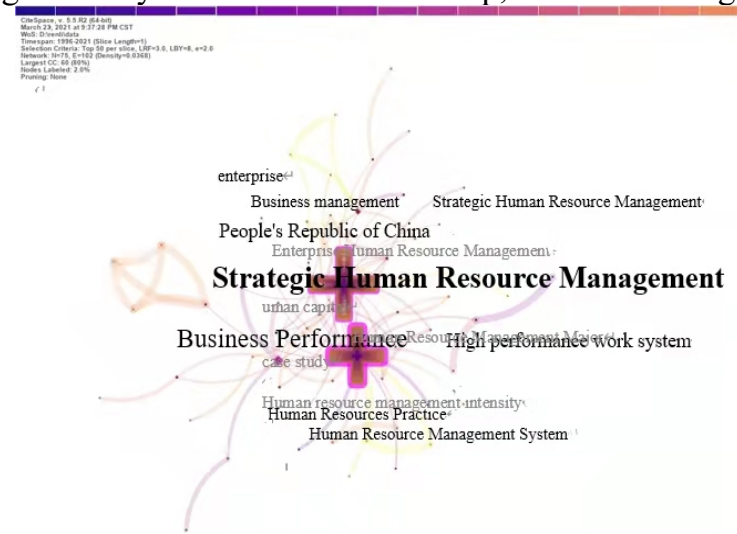

Fig. 4 Keyword co-occurrence knowledge map

Analyzing Figure 2, there are 187 nodes, which represent the number of keywords, and there are 504 node connections, which represent the links between keywords, and the network density is 0.029 . The line between nodes represents the relationship between keywords. The line indicates that two keywords appear together in a document. The thickness indicates the number of occurrences, and the color corresponds to the time of first appearance, varying from dark to light Represents the change in time from early to recent. The thicker the line, the denser it is. Table 3 is obtained by sorting out the keyword frequency and centrality data obtained by the software. The word frequency analysis method is a method of using the frequency of keywords or subject terms in a certain research field to study the development trends and research hotspots of this field. In the bibliometric method, centrality represents the "mediation" role of keywords in the graph, and the nodes between different groups are the research issues surrounding the field. Table 3 shows keywords that appeared 5 times or more from 1994 to 2018. To sort out and summarize high-frequency keywords, the research hotspots under the theme of domestic human resource management practice mainly include the following: first, macro research; second, micro research; third, performance; fourth, research methods; Fifth, research perspective, and sixth, function. As shown in Table 4. Regarding the occurrence of practical phrases in the three high-frequency keywords, it can be seen that the existing scholars' research on the practical application of theoretical support is a current hot spot, and the practice of human resource management has important guiding significance for enterprise human resource management [6].

Table 3 Frequency and centrality of high-frequency keywords

\begin{tabular}{cccccc}
\hline Keyword & Freq & Centrality & Keyword & Freq & Centrality \\
\hline $\begin{array}{c}\text { human resource } \\
\text { Management }\end{array}$ & 311 & 0.7 & $\begin{array}{c}\text { High-performance } \\
\text { human resource } \\
\text { practices }\end{array}$ & 8 & 0.06 \\
\hline
\end{tabular}




\begin{tabular}{|c|c|c|c|c|c|}
\hline $\begin{array}{c}\text { Human Resource } \\
\text { Management Practice }\end{array}$ & 118 & 0.4 & $\begin{array}{l}\text { Human Resource } \\
\text { Management Model }\end{array}$ & 6 & 0.06 \\
\hline Human Resources & 77 & 0.31 & $\begin{array}{l}\text { Organizational } \\
\text { support }\end{array}$ & 6 & 0.06 \\
\hline $\begin{array}{c}\text { Strategic Human Resource } \\
\text { Management }\end{array}$ & 87 & 0.21 & $\begin{array}{l}\text { Human Resources } \\
\text { Practice }\end{array}$ & 18 & 0.05 \\
\hline $\begin{array}{l}\text { Organizational } \\
\text { Performance }\end{array}$ & 57 & 0.17 & $\begin{array}{l}\text { Human Resource } \\
\text { Management System }\end{array}$ & 18 & 0.05 \\
\hline Business Performance & 51 & 0.13 & $\begin{array}{c}\text { Enterprise Human } \\
\text { Resource } \\
\text { Management }\end{array}$ & 16 & 0.04 \\
\hline $\begin{array}{c}\text { High performance work } \\
\text { system }\end{array}$ & 31 & 0.09 & human capital & 16 & 0.03 \\
\hline People's Republic of China & 17 & 0.09 & $\begin{array}{l}\text { Human Resource } \\
\text { Management Major }\end{array}$ & 12 & 0.03 \\
\hline enterprise & 44 & 0.08 & case study & 6 & 0.03 \\
\hline Business management & 34 & 0.08 & $\begin{array}{l}\text { Human resource } \\
\text { management } \\
\text { intensity }\end{array}$ & 5 & 0.02 \\
\hline $\begin{array}{c}\text { Strategic Human Resource } \\
\text { Management }\end{array}$ & 25 & 0.06 & & & \\
\hline
\end{tabular}

Table 4 Keyword subject classification table

\begin{tabular}{|c|c|}
\hline theme & Keywords (frequency) \\
\hline Macro & $\begin{array}{l}\text { Human Resource Management (311); Strategic Human Resource Management } \\
\text { (87) } \\
\text { Strategic Human Resource Management (25); Human Resource Management } \\
\text { Model (6) }\end{array}$ \\
\hline Micro & $\begin{array}{l}\text { Organizational support (6); human capital (16); intensity of human resource } \\
\text { management (5) }\end{array}$ \\
\hline Performance & $\begin{array}{l}\text { Organizational performance (57); corporate performance (51); high-performance } \\
\text { work system ( } 31) \\
\text { High-performance human resource management }(8)\end{array}$ \\
\hline method & Case study (6) \\
\hline Perspective & $\begin{array}{l}\text { People's Republic of China (17); Enterprise (44); Enterprise Management (34) } \\
\text { Human Resource Management Major (12) }\end{array}$ \\
\hline Function & $\begin{array}{l}\text { Human Resource Management Practice (118); High-Performance Human } \\
\text { Resource Management Practice (8) } \\
\text { Human Resource Practice (18) }\end{array}$ \\
\hline
\end{tabular}

\subsection{Evolutionary process and research hotspot knowledge map analysis}

This study uses the time zone analysis and imaging methods of citespace software to integrate 1066 documents from 2014 to 2018 to form a knowledge map characterized by the development and evolution of keywords. In Figure 5, "Enterprise Management",
"Enterprise Human Resource Management", "Human Resource Management", "Human Resource Management Practice [7]", "Strategic Human Resource Management [8]", and "Human Resource Model" are formed in Figure 5. "Human Resource Practice [9]", "Human Resource Management Mode", "Human Resource Management Intensity [10]", "Big Data", and "Organizational PsychologicalOwnership".

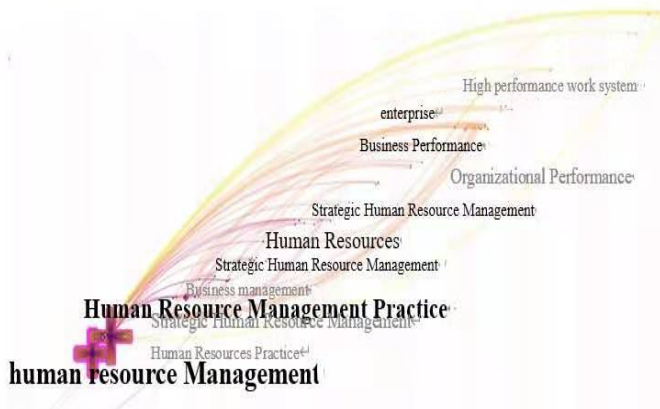

Fig. 5 Keyword time zone knowledge map 


\section{Conclusion}

In this paper, through a visual analysis of research data on the theme of human resource management practices in the CNKI core journal database from 1994 to 2018, it explores the domestic authoritative authors, publishing organizations, and institutions that have had a significant impact on human resource management research in the past 25 years. The focus of research on human resource management practice, Through research, clarified the research context of human resource management practice as the theme, grasped the development of theory and practice, and provided support for the current stage of human resource management research and innovation

The authors are grateful for the support received from Liaoning Provincial Department of Education Science Research Funding Project "Study on the Mechanism and Implementation Path of Interaction Empowerment of Social Networks and Knowledge Networks to Technological Innovation" (J2020082); Liaoning Provincial Department of Education Special Program "Improving the Innovation Capability of Liaoning's Equipment Manufacturing Industry for Intelligent Manufacturing" Research on Mechanism and Path" (2017J066); Dalian Academy of Social Sciences' 2020 major research project "Research on Dalian's Social Risk Perception and Epidemic Prevention and Control Guidance Mechanism in Response to Public Security Incidents under the Background of Big Data" (2020dlsky090)

\section{References}

1. Shiffrin,Katy Borner. Mapping knowledge domains[J]. Proceedings of the National7 Academy of Sciences, 2004(4):5183-5185.

2. Zeyuan Liu. Science and Technology Management Discipline Construction Based on Knowledge Graph — Report on the Discipline Construction of the Doctoral Program of Science of Dalian University of Technology [A]. Chinese Science and Technology Policy Research Association. The 4th Chinese Science and Technology Proceedings of the Annual Conference of the Policy Research Association Luigi T. De Luca, Propulsion physics (EDP Sciences, Les Ulis, 2009)

3. Hao Zhipeng, Zhang Suodi, Wang Jianxiu. Comparative research on entrepreneurial learning at home and abroad and its contextualization enlightenment in China [J]. Journal of Management, 2018, 15(09): 1411-1422.

4. Chen Xiaojin. Research on the implementation and application of strategic human resource management[J]. Human Resources Development, 2018(20):81-82.

5. Zhou Jinfan, Zhang Guanglei. Research on the impact mechanism of green human resource management practices on employees' green behaviors-Based on the perspective of self- determination theory[J]. China Human Resources Development, 2018, 35(07): 20-30.

6. Chen Lifen, Jin Can. The impact of highperformance human resource practices on task performance and innovative behavior: the role of organizational psychological ownership and interactive fairness[J]. China Human Resources Development, 2018, 35(06): 144-155.

7. Zhou Jinfan, Zhang Guanglei. Research on the impact mechanism of green human resource management practices on employees' green behaviors - Based on the perspective of selfdetermination theory[J]. China Human Resources Development, 2018, 35(07): 20-30.

8. Chen Xiaojin. Research on the implementation and application of strategic human resource management $[\mathrm{J}]$. Human Resources Development, 2018(20):81-82.

9. Chen Lifen, Jin Can. The impact of highperformance human resource practices on task performance and innovative behavior: the role of organizational psychological ownership and interactive fairness[J]. China Human Resources Development, 2018, 35(06): 144-155.

10. Jia Jianfeng, Jiao Yuxin, Zhao Ruonan. The influence of authentic leadership on the intensity of human resource management: the mediating role of employee's suggestive behavior and the moderating role of organizational political perception[J]. Journal of Northeastern University (Social Science Edition), 2018, 20(04):373-379. 